\title{
Microstructure and Polarization Resistance of Thermally Sprayed Composite Cathodes for Solid Oxide Fuel Cell Use
}

\author{
K. Barthel, S. Rambert, and St. Siegmann
}

(Submitted 29 February 2000)

\begin{abstract}
Porous composite cathode coatings containing $\left(\mathrm{La}_{0.8} \mathrm{Sr}_{0.2}\right)_{0.98} \mathrm{MnO}_{3}(\mathrm{LSM})$ and $\mathrm{ZrO}_{2}-12 \% \mathrm{Y}_{2} \mathrm{O}_{3}$ (YSZ) were prepared by vacuum plasma spraying (VPS) and flame spraying (FS) on prefabricated substrate-based planar solid oxide fuel cells (SOFC) with $60 \mathrm{~mm}$ iu diameter. Microstructural observations reveal the open porosity of the catbode coatings and prove qualitatively the compositional gradient from YSZ-LSM composite to pure LSM. The electrochemical hehavior was investigated by impedance spectroscopy. The results of graded cathodes compared with nongradient and bilayered ones are discussed with respect to the cathodic polarization resistance between 750 and $9500^{\circ} \mathrm{C}$. Bilayered cathodes indicate the lowest cathodic losses followed by the graded ones and the conventional composite. Flame sprayiug as a rarely used processing tool for SOFC components can provide cathodes of high electrochemical performance.
\end{abstract}

$\begin{array}{cl}\text { Keywords } & \begin{array}{l}\text { compositionally graded cathodes, flame spraying, im- } \\ \text { pedance spectroscopy, microstructure, perovskite, vac- } \\ \text { uum plasma spraying }\end{array}\end{array}$

\section{Introduction}

Solid oxide fuel cells (SOFCs) enable the direct conversion of the chemical energy of hydrocarbons into electricity. As they have high electrical efficiencies of up to $70 \%$ and low emissions, they represent a good potential for the cogeneration of heat and electrical power in an ecologically more acceptable way. Although this technology promises very stable long-term operation, without use of corrosive liquids and novable parts, the application still has not been realized because of the relatively high manufacturing costs. A major approach toward cost savings is the reduction of the high operating temperatures from the currently used 900 to $10000^{\circ} \mathrm{C}$ to intermediate temperatures (ITs) of 650 to $800^{\circ} \mathrm{C}$. This step would allow the replacement of interconnections consisting of expensive ceramics or high-temperature $\mathrm{Ni} / \mathrm{Cr}$-based alloys by common $\mathrm{Cr}$-rich ferritic steels. Because of slower kinetics of the cell reaction, however, the power output decreases with lower working temperatures. Thus, IT operation requires a membrane-electrodes assembly (MEA) of high electrochemical performance. As the latter is primarily limited by the cathode reaction, "I] major attention within the present work has been given to the improvement of the cathode.

\section{Composite Cathodes}

The SOFC cathodes must show high electronic and ionic conductivity, sufficient thermal and chemical stability at high tem-

K. Barthel, Fraunhofer Institut Werkstoff-und Strahltechnik, D-0|277 Dresden, Germany; S. Rambert, Swiss Federal Institute of Technology Lausanne, EPFL, Lausanne CH-1015, Switzerland; and St. Siegmann, Swiss Federal Laboratories for Materials Testing and Research, EMPA, Thun CH 2602, Switzerland. peratures in air, and good compatibility with the electrolyte. Strontium-doped lanthanum manganite (LSM) with a perovskite-type structure is one of the materials that satisfactorily meets these requirements for cells that operate above $900^{\circ} \mathrm{C} \cdot .^{[2]}$ Numerous publications have shown that additions of oxygenion-conductive electrolyte material (mostly yttria-stabilized zirconia (YSZ) or cerium-gadolinium-oxide (CGO)) to the perovskite, which leads to the formation of a composite cathode, can' improve the cathodic performance further. ${ }^{[3-7]}$ Analog to alkaline fuel cells, where the liquid electrolyte completely penetrates the electrodes, the reaction area that appears as pseudotriple phase boundary (TPB) of electrolyte, electrode, and gas phase is considerably enlarged. ${ }^{|4|}$ Taking into account the higher melting point of $Y S Z$ at $2550^{\circ} \mathrm{C}$, the addition of this material is expected to improve the morphological stability during operation, as the open porosity will not diminish by sintering and creep. To derive the benefit of additional catalytically active sites, a two-phase percolation in the LSM and in the ion conductor must be obtained. Thus, the lowest cathodic polarization resistance occurs at a volume ratio of about $1: 1 .^{141}$

Despite these advantages, we must consider that the overall electronic conductivity decreases by about a factor of 10 because of the YSZ or CGO addition. Because of this, the pure electronic current collection is considerably hindered. The two tasks described, however, charge transfer and current collection, take place at geometrically opposite parts, at the electrolyte-cathode interface and the top of the cathode, respectively. Based on this mechanism, two-layer cathodes, consisting of a composite part as well as a pure perovskite part, have been successfully applied. ${ }^{|8, y, 10|}$

Taking into account that the thermal expansion coefficient of both phases differs by 30 to $50 \%$, it can be expected that these cathodes always suffer from a thermomechanical mismatch between the two layers. In this regard, a continuous stepwise transition of the composite concentration could optimize the total cathode performance further. In the present paper, we also investigated how a graded transition of the composite phase to 


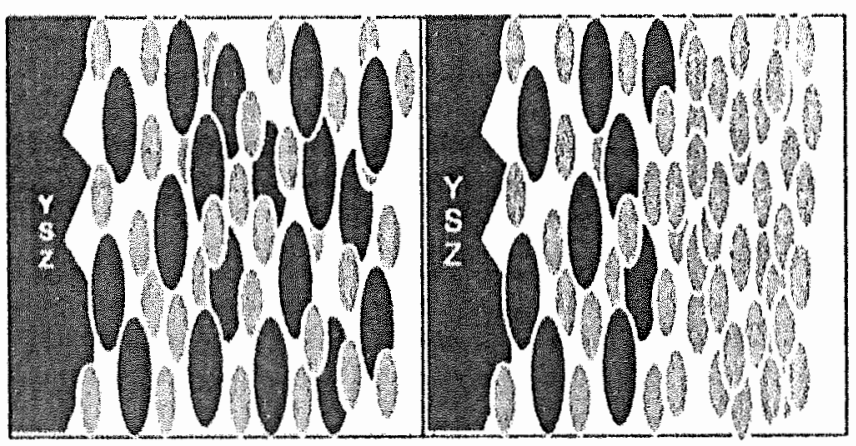

A

B

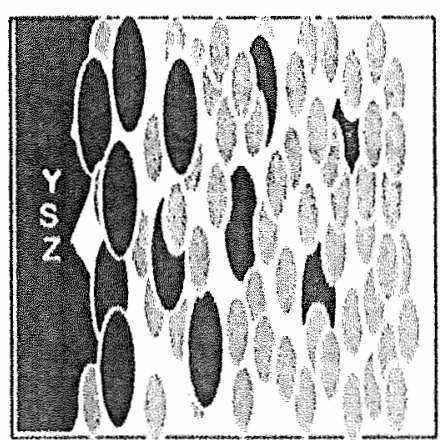

C

lig. I Schematic or (a) porous composite, (b) two-layer, and (c) graded composite cathodes of LSM-YSZ

pure LSM within the cathode can influence the electrochenical performance. The results have been compared to those of nongradient and two-layer structures (Fig.1).

\section{Thermal Spray Processing}

Various preparation techniques have been used to manufacture SOFC components; however, they are often relatively expensive or time consuming. For commercial applications of SOFC systems, vacuum plasma spraying (VPS) represents a promising processing route, and, therefore, it has already been applied by many groups. ${ }^{[11,12,13]}$ lt allows the porosity-controlled deposition of the entire MEA in a single processing step. For the deposition of porous cathodes, however, flame spraying (FS), as a simpler process in an atmospheric environment, would be an even more economical choice. Thus, composite calhodes have been processed by both techniques in this work.

The advantages of thermal spraying for the manulacturing of functionally graded materials within the millimeter-thickness range were already reported in Ref 14 through 17 and others. Compositionally graded coatings in the thickness range of 40 to $80 \mu \mathrm{m}$ can only by realized by thermal spraying, as the molten powder particles of a diameter of 20 to $50 \mu \mathrm{m}$ flatten by a factor of 5 to 10 at the impact on the substrate surface. Thus, the spray conditions had to be set up to deposit the total cathode thickness within five to six spray passes. This creates the gradient of five to six layers $10 \mu \mathrm{m}$ thick each. The actual composition of each layer is given by the $\mathrm{PC}$-controlled powder feed rates during the spray passes.

The composite cathodes have been fabricated using monolithic LSM and YSZ powders as well as a mixture of 50:50 vol.\% of both. The LSM and YSZ powders were obtained from PSC (Praxair Speciality Ceramics, Woodinville, USA) and MEL Chemicals Ltd. (Manchester, United Kingdom), respectively. The composite one was prepared at EMPA by milling LSM and YSZ together to a size smaller than $1 \mu \mathrm{m}$ followed by spray drying and sintering. They all had to fit the size range of 20 to $50 \mu \mathrm{m}$.

For VPS, a Medicoat AG (Mägenwie) (CH) $50 \mathrm{~kW}$ DC-VPS equipment with a powder feeder for four different powders (Fig.

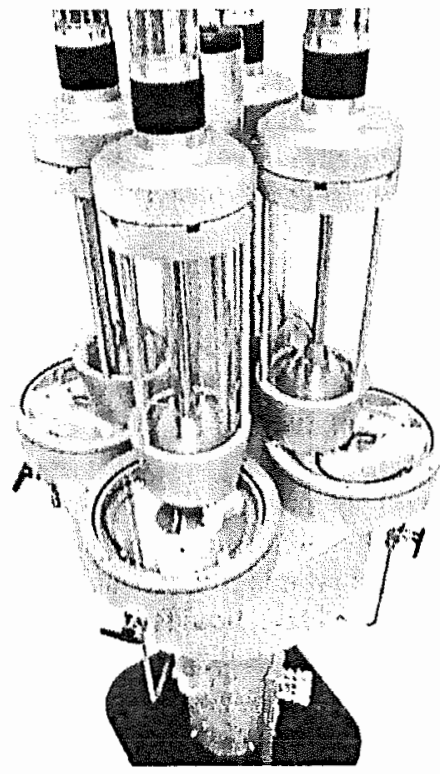

Fig. 2 Powder feed system for four powders by Medicoat AG

2) was employed. The spray parameters were adapted to the powder properties within the ranges of 100 mbar chamber pressure, 275 to $350 \mathrm{~mm}$ spray distance, 40 to $50 \mathrm{lpm}$ Ar primary plasma gas flow, 0.5 to $1 \mathrm{lpm} \mathrm{H}_{2}$ secondary plasma gas flow, and 16 to $25 \mathrm{~kW}$ electrical input power. Flame spraying was carried out using a CastoDyn DS 8000 gun fabricated by Castolin SA. For the deposition of graded coatings, the on-top powder feedstock was replaced by the connection for the external twin-dosing system by Sulzer Metco AG, which allows the feeding of two powders. The composite cathodes were deposited on planar porous metal-supported cells $60 \mathrm{~mm}$ in diameter, which have been prefabricated as described in Ref 18. These components can be understood as minicells corresponding to the Sulzer HEXIS concept, ${ }^{[19]}$ consisting of metallic interconnector and gas distributor, anode cermet, and YSZ electrolyte. Each cell has been completed with four sector-shaped cathodes of $1.48 \mathrm{~cm}^{2}$ of 


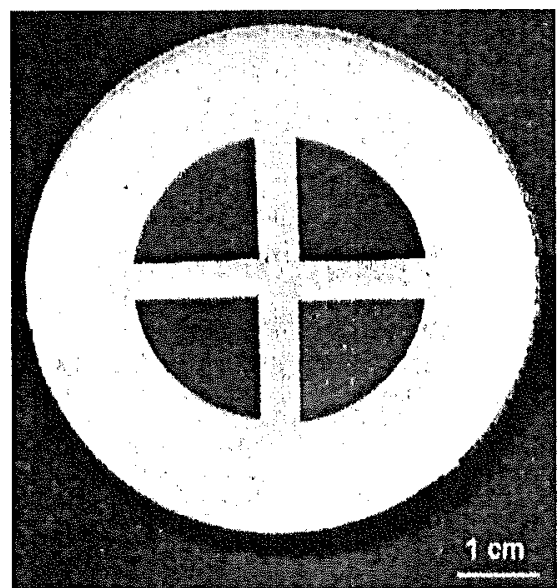

Fig. 3 Top view of sector-shaped graded composite cathodes on 60 mm diameter cells (electrolyte appears white)

surface area each (Fig. 3) by applying a special masking lechnique. The quadrants were separately coated with different compositions, one following the other, by turning the masking sheet 90 deg each time.

\section{Microstructure and Composition}

After deposition, $x$-ray diffraction (XRD) measurements did not indicate any formation of the undesired La-Zirconate phases. Destructive microstructural investigations have been carried out using coatings on stainless-steel sheets that have masked the cell during the deposition of the desired cathode area. The cathode microstructure was investigated by preparing metallographic sections and by scanning electron microscopy (SEM) top-view observations. Figures 4 and 5 illustrate that the more finely dispersed microstructure and pore structure is obtained by VPS Cathodes created by FS also contain some microcracks. Both phases, LSM and YSZ, can barely be optically distinguished by their gray scale (the lighter gray phase is the YSZ). The micrographs show qualitatively how the YSZ content diminishes towards the surface of the cathodes.

\section{Electrochemical Behavior}

The electrochemical measurements have been carried out by means of a specially adapted SOFC bench test, where hydrogen and air can be separately fed to a cell at temperatures of up to $1000^{\circ} \mathrm{C}$. The four cathodes of the cell were contacted, relerence points added, and the cell heated and polarized to $0.5 \mathrm{~V}$. The polarization resistances were obtained by impedance spectroscopy using a Zahner IM6 spectrometer. The impedance spectroscopy superimposes a small amplitude signal (generally sinusoidal) to the direct current of the cell. It records the real part (pure ohmic contribution) and the imaginary part (capacitive and inductive contributions) of the potential response as a function of the signal frequency applied to the electrochemical device. In favorable cases, it allows effective separation of the different contributions of the various electrochemical losses, because the response times

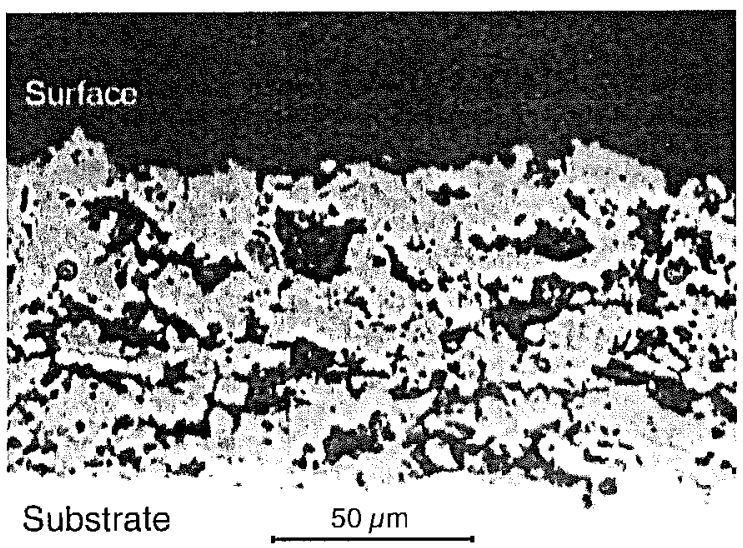

(a)

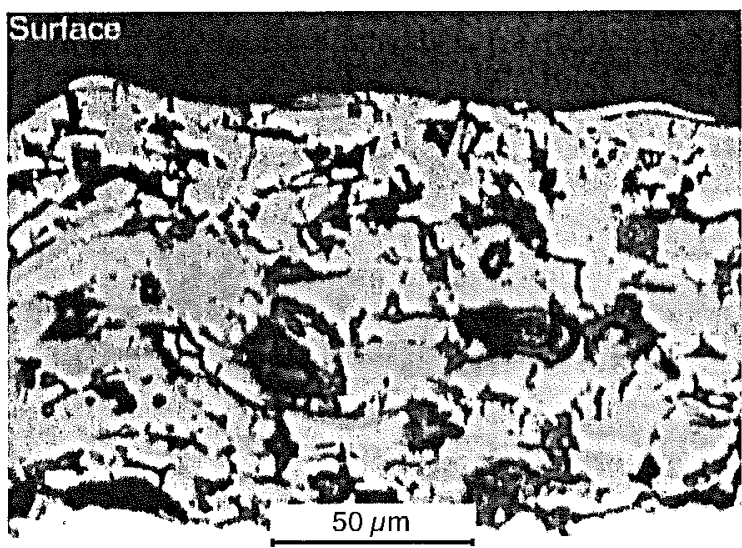

Substrate

(b)

Fig. 4 (a) Polished section of a graded LSM-YSZ composite cathode processed by VPS. (b) Polished section of a graded LSM-YSZ composite cathode processed by FS.

related to the perturbation differ greatly depending on the type of electrochemical loss. One expects the following kinds of distribution, depending on the frequency:

- ionic/electronic conduction losses (electrolytic resistance) at a high-frequency range;

- interface (electrodes) reaction losses (charge transfer) at a medium-frequency range;

- mass transfer losses (gas diffusion in the porous electrode) at a low-frequency range.

One must be aware that a part of a composite cathode (the cathode in the macroscopic, physical sense) actually behaves as an electrolyte (in the electrochemical sense). This is even true for homogencous cathodes, because of the mixed conducting behavior of the perovskites. As regards the cathode performance calculation (polarization resistance), the whole electrolyte-like contribution, in the electrochemical sense, was subtracted. The extra electrolyte part resulting from the composite cathode was small, however, and the performance increase resulting from the composite structure was quile effective. 


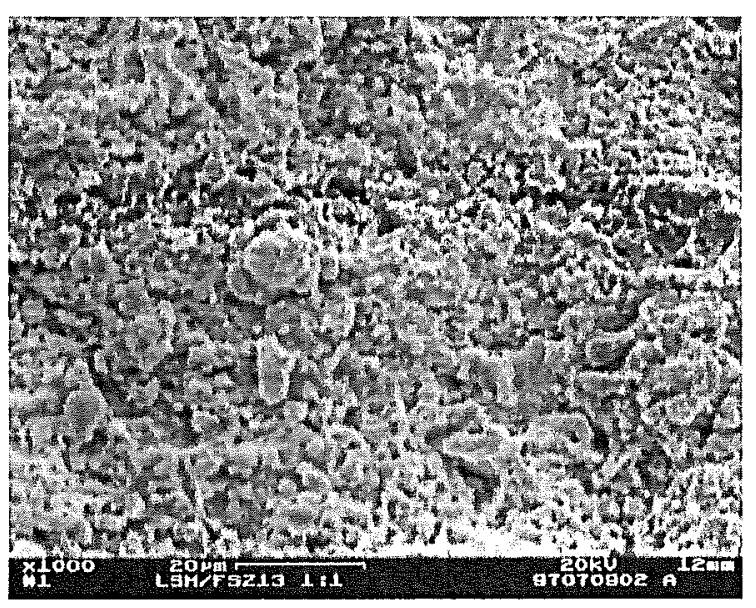

(a)

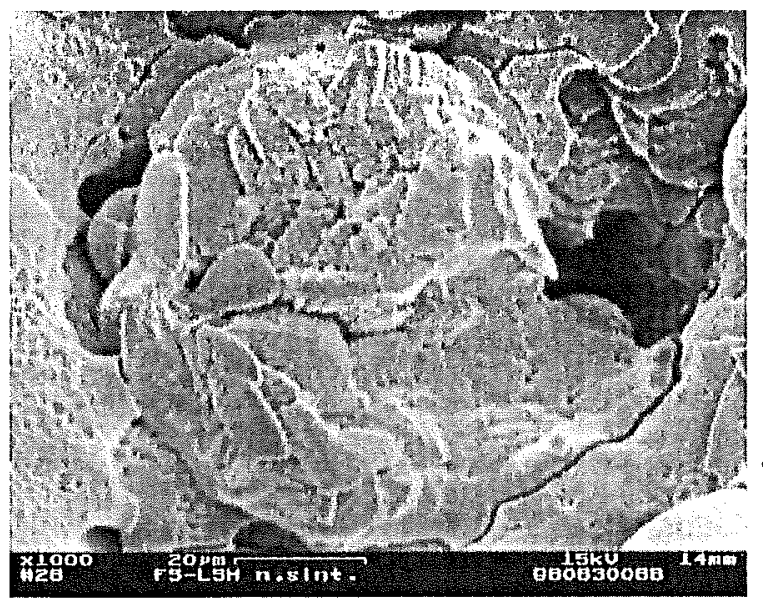

(b)

Fig. 5 (a) SEM top view of graded LSM-YSZ composite cathode processed by VPS. (b) SEM top view of graded LSM-YSZ composite cathode processed by FS

Thin, solid electrolytes do not allow for easy separation of the anodic and the cathodic contributions. Moreover, the usual reference electrode (actually a small auxiliary cathode that is kept nonpolarized using a high-resistance multimeter) does not operate correctly on thin, asymmetrical cells, that is, on cells having unequal anode and cathode areas, or for slightly shifted electrodes. The measurement necessitates a specially designed reference electrode that is not yet available. Making a quasi-symmetric cell is another way to solve the problem. This cell has an insulating layer deposited on the anode cermet, that is, covering the area located between the reference point and a point corresponding to the edge of the cathode location. A symmetrical VPS cell of this type was actually produced and showed a significant improvement in the measurements, but failed to meet all our expectations. It suggested that the anode contribution was low with respect to the cathode(s). In the Arrhenius plots shown in Fig. 6 and 7, the cathode polarization resistances are shown as a function of the temperature in the range of 750 to $950^{\circ} \mathrm{C}$. The inverse-proportional behavior of the logarithm of the polarization resistance is a known consequence of the slower kinetics of the cathodic reaction at lower operating temperatures.

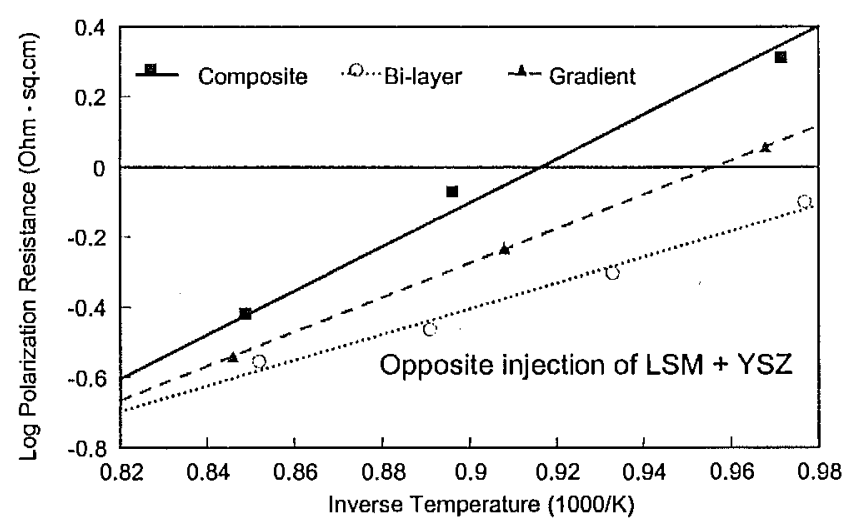

Fig. 6 Polarization resistances of VPS cathodes by impedance spectroscopy

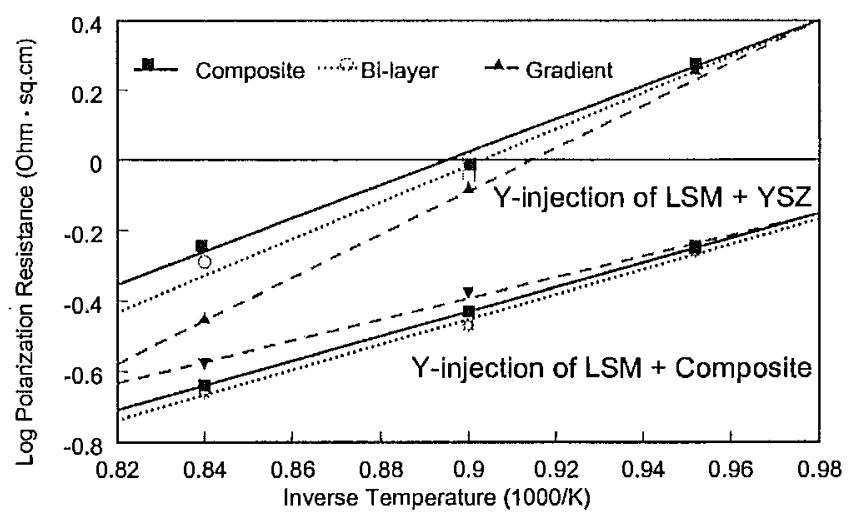

Fig. 7 Polarization resistances of FS cathodes by impedance spectroscopy

The activation energy of the cathode can be calculated by means of the slopes obtained. In the present cases, values between 0.75 and $0.9 \mathrm{eV}$ have been typically obtained.

For the VPS deposition, the polarization resistance compared to the composite is clearly reduced by using gradient or bilayer cathodes, with the latter having the lowest polarization. Two powder feed techniques have been applied for the FS process, which gave different results. Adjusting the local composition by mixing with a Y-shaped tube during injection (Y-injection) gave higher polarizations than those obtained with VPS, whereas the Y-injection of LSM-YSZ composite granulated powder resulted in very low polarizations. In the first case, the graded cathode was slightly superior to the others. The second cell with very low losses did not show an improvement by applying a layered gradient.

Finally, we conclude that in all cases the bilayer and/or graded cathodes give the lowest polarization resistances, which means improved cathode performance. For two of three cells, the clearest improvement was obtained by the bilayer type. The results confirm again the assumption made in Section 2 that a volume ratio of nearly 1:I of LSM and YSZ may lead to the lowest possible polarization resistance. Within bilayer-type cathodes, the $50: 50 \%$ composition is present from the interface toward the electrolyte up to 20 to $40 \mu \mathrm{m}$ thick and thus represents an ex- 
tended TPB length. Graded cathodes with a linear composition profile, in comparison, may have a considerably smaller than $50: 50 \%$ vol. $\%$ of LSM-YSZ (within a few microns thickness) and in consequence a smaller TPB length, because of the direct composition change from 50:50\% LSM-YSZ to pure LSM that starts very close to the interface.

If the total length of the TPB is primarily determining the catthodic polarization, the composition profiles of the graded cathodes still must be adapted. This could be realized, for example, by applying an $\mathrm{S}$-shaped profile with a larger $50: 50 \%$ zone close to the electrolyte, followed by a steeper gradient toward pure LSM for current collection.

\section{Summary and Outlook}

Porous composite cathodes of $\left(\mathrm{La}_{0.8} \mathrm{Sr}_{0.2}\right)_{0.98} \mathrm{MnO}_{3}(\mathrm{LSM})$ and $\mathrm{ZrO}_{2}-12 \% \mathrm{Y}_{2} \mathrm{O}_{3}$ (YSZ) were successfully deposited by thermal spray processes. Furthermore, compositionally graded deposits of 40 to $80 \mu \mathrm{m}$ thick have been realized applying the multilayer principle. The composition profiles obtained can be qualitatively verified by their microstructures. The electrochemical performance of the cathodes, evaluated by impedance spectroscopy, indicates significant improvements, especially for the bilayer technique, whereas the concentration profiles of the multilayer gradients still must be optimized. Flame spraying as a new processing tool in this field seems to have good potential for future applications as it provides encouraging results within an advantageous cost range. The good experience resulting from thermal spraying of composite cathode coatings by will be further investigated within the Sulzer Hexis SOFC development.

\section{Acknowledgments}

The authors thank Dr. B. Gut (EMPA), for providing the composite powder and the fuel cell group at LPI-EPFL, and the thermal spray group at EMPA Thun for experimental work and discussions. Financial support by the Swiss Federal Office for Energy is gratefully acknowledged.

\section{References}

1. H. Lauret and A. Hammou: J. Eur: Ceram. Soc., 1996, vol. 16, p 447-51, 2. N.Q. Minh: J. Am. Ceram. Soc., 1993, vol. 76, p 563-88.
3. S. Sunde: IOth SOFC Workshop: Solid Oxide Fuel Cells under Real Operating Conditions, A.J. McEvoy, ed., EPFL, Lausame, 1997, p $192-$ 95.

4. T. Kenjo and M. Nishiya: Solid State Ionics, 1992, Vol 57, p 295-302.

5. H. Kamata, A. Hosaka, Y. Ikegami, J. Mizusaki, and H. Tagawa: Ist Eur. Solid Oxide Fuel Cell Forum, U. Bossel, ed., European Fuel Cell Forum, Lucerne, Switzerland, 1994, p 725-33.

6. Y. Shibuya and H. Nagamoto: 5th Int. Symp. on Solid Oxide Fuel Cells (SOFC-V), U. Stimming et al., eds., The Electrochemical Society, Pennington, NJ, 1997, p 5 J0-19.

7. M.J.L. Østergård, C. Clausen, C. Bagger, and M. Mogensen: Electrochinica Acta, 1995, vol. 40, p 1971-81.

8. M. Juhl, S. Primdahl, and M. Mogensen: 17 th Ris $\emptyset$ Iht. Symp. on Materials Science, F.W. Poulsen et al., eds., Ris $\emptyset$ National Laboratory, Roskilde, Demmark, 1996, p 295-300.

9. G.M. Christie, F.H. van Heuveln, and F.P.F. van Berkel: $17 t h$ Ris $\phi$ Int. Symp. on Materials Science, F.W. Poulsen et al., eds., Ris $\emptyset$ National Laboratory, Roskilde, Denmark, 1996, p 205-11.

10. P. Holtappels, M. Juh]-Jørgensen, S. Primdahl, M. Mogensen, and C. Bagger: 3rd Eur. Solid Oxide Fuel Cell Fortum, P. Stevens, ed., European Fuel Cell Forum, Oberrohrdorf, Switzerland, 1998, p 311-20.

11. J. Moens and H. Gruner: 3rd Eur: Solid Oxide Fuel Cell Fortun, P. Stevens, ed,, European Fuel Cell Forum, Oberrohrdorf, Switzerland, 1998, p 115-22.

12. R. Henne, G. Schiller, V. Borck, M. Mueller, M. Lang, and R. Ruckdäschel: in Thermal Spray: Meeting the Challenges of the 21 st Century, C. Coddet, ed., ASM International, Materials Park, OH, 1998, p 933-38.

13. H.C. Chen, J. Heberlein and T. Yoshioda: in Thermal Spray: Meeting the Challenges of the 2Ist Century, C. Coddet, ed., ASM Intermational, Materials Park, OH, 1998, p 1309-14.

14. A. Salito and G. Barbezat: 3rd Jht. Symp. on Structural and Functional Gradient Materials, Ilschner et al., eds., Presses Polytechniques et Universitaires Romandes, Lausanne, 1994, p 123-28.

15. J. Musil, M. Alaya, and R. Oberacker: J. Thermal Spray Technol., 1997, vol. 6, (4), p 449-55.

16. F. Blein and A. Freslon: in Meeting the Challenges of the 2Ist Century, C. Coddet, ed., ASM International, Materials Park, OH, 1998, p 125963.

17. K.A. Khor, Y.W. Gu \&, and Z.L. Dong: 15th Int. Thermal Spray Conf-Thermal Spray: Meeting the Challenges of the 21st Century, C. Coddet, ed., ASM International, Materials Park, OH, 1998, p 1543-48.

18. H. Gruner, and J. Moens: 2nd Eur. Solid Oxide Fuel Cell Forum, B. Thorstensen, ed., European Fuel Cell Forum, Oberrohrdorf, Switzerland, 1996, p 261-67.

19. R. Diethelm, J. Brun, T. Gamper, M. Keller, R. Kruschwitz, and D. Lenel: 5th Int. Symp. on Solid Oxide Fuel Cells (SOFC-V), U. Stimming et al., eds., The Electrochenical Society, Pennington, NJ, 1997, p 79. 88. 